\title{
Optimization of Energy Density in Girders under Pure Bending with an Extruded Monolithic Cross-Section
}

\author{
Daniel Fernández Caballero1* ${ }^{*}$, Víctor Rodríguez de la Cruz², Juan Manuel Munoz Guijosa² \\ ${ }^{1}$ Department of Mechanical Engineering, Universidad Pontificia ICAI, Madrid, Spain \\ ${ }^{2}$ Department of Mechanical Engineering, Escuela Técnica Superior de Ingenieros Industriales, Universidad Politécnica de Madrid, \\ Madrid, Spain \\ Email: *daniel.fernandez.caballero@gmail.com
}

How to cite this paper: Caballero, D.F., de la Cruz, V.R. and Guijosa, J.M.M. (2019) Optimization of Energy Density in Girders under Pure Bending with an Extruded Monolithic Cross-Section. World Journal of Mechanics, 9, 53-66.

https://doi.org/10.4236/wjm.2019.93004

Received: March 8, 2019

Accepted: March 28, 2019

Published: March 31, 2019

Copyright $\odot 2019$ by author(s) and Scientific Research Publishing Inc. This work is licensed under the Creative Commons Attribution International License (CC BY 4.0).

http://creativecommons.org/licenses/by/4.0/

\begin{abstract}
This article proposes use of extruded compound materials with optimized resistant cross-sections as an alternative, in this case, seeking the maximum energy density as a design criterion. The advantage of this proposal is that it extends the life cycle and decreases fatigue issues.

\section{Keywords}

Pure Bending, Energy Storage, Composite Material, Extruded Cross-Section, Design Optimization
\end{abstract}

\section{Introduction}

Traditionally, girders subjected to pure bending have been optimized based on either the material or the geometry of the resistant cross-section. Normally, the resistant cross-section in IPN/UPN sections or in sandwich panels is optimized. In regard to the materials, unidirectional compound materials in which the allowable compression stress is approximately half the allowable tensile stress may be used. This type of material may be used in pure bending, but use in combined load states may cause shear issues and loss of properties in the fiber's transversal length. In regard to the resistant cross-section, different studies have been done on the influence of the type of cross-section with design criteria such as the resistance or energy storage.

The classic optimization of girders subjected to bending has traditionally started with a rectangular cross-section. The classic optimization criterion is the maximum allowable stress on all of the fibers of the resistant cross-section [1] [2] 
and [3]. There are two possible design alternatives, one of which is the optimization of the material of the resistant cross-section and the other the shape of the cross-section itself [4]. This article will take into account both this criterion as well as the stored energy generated by the bending of the girder.

On one hand, the use of new composite materials, with a maximum allowable stress and minimal Young's Modulus, makes it possible to optimize the first one of these variables in the material to be used [5]. On the other hand, the optimization of the second design variable, the geometry of the resistant cross-section, has classically been achieved by optimizing the central part of the resistant cross-section, as it is subjected to less stress, under bending loads. The optimization can be achieved with IPN/UPN profiles [6] [7] and [8], optimization of the central parts of the profiles [9] [10] [11] [12] and [13], or by using sandwich structures with different materials and mechanical properties in their layers [14] and [15].

This article presents both solutions, with use of a monolithic extruded crosssection made of compound materials, as will be shown in the further development below. There are few references regarding this manufacturing process and most refer to the wood industry [16] [17] and [18]. Very few references were found on fibers with strong mechanical properties, such as the unidirectional fiberglass and carbon fibers that are proposed.

In addition, the girder bending tests can be done using three-point or fourpoint test machines or special modifications to them [19]. The final goal of all of these is to test pure bending, but these types of tests limit the pure bending zone in one way or another. The girder's useful length of pure bending is limited by external effects such as shear. There are specific test machines and tests that subject $100 \%$ of the test sample to pure bending [19]. The type of machine that is used is unimportant for the development of this work; it is assumed that pure bending is applied along the entire length.

\section{Optimization of Energy Storage by the Beam}

The first step in this process consists of redesigning the rectangular monolithic cross-section that is used, in such a way as to increase the energy density. This objective can be achieved easily by making all of the sections work at $100 \%$ of their capacity; in other words, the allowable compression stress of the material is achieved on the skins furthest from the neutral fiber. This is the case because for a cross-section made up of a single material, no matter how much the position of the neutral fiber is changed, this value is always reached before the admissible tensile stress. Once the first of the aforementioned stresses has been achieved, the objective will therefore be to maximize the second as much as possible.

The base data for the pure bending study of the girder will be the change of curvature, torque, and the characteristics of the material. The resistant crosssection of the girder can be calculated (Equations (1)-(3)).

$$
\Delta \varphi=\frac{M}{E * I_{Z}}
$$




$$
\begin{gathered}
\sigma_{a d m C}=\frac{M * e / 2}{I_{Z}} \\
I_{Z}=\frac{1}{12} b * e^{3}
\end{gathered}
$$

The energy stored in the girder can then be calculated with this data (Equation (4)). The energy density is calculated by using the aforementioned equations and dividing by the weight of the girder.

$$
\begin{gathered}
U=\iiint \frac{1}{2} \frac{\sigma^{2}}{E} \mathrm{~d} V \\
\frac{U}{P}=\frac{2 *\left(\frac{\sigma_{a d m C}}{e / 2}\right)^{2} \frac{(e / 2)^{3}}{6 E}}{\rho * e}=\frac{1}{6} \frac{\sigma_{a d m C}^{2}}{\rho * E}
\end{gathered}
$$

The increase in energy density with a single material can be achieved by increasing the thickness of the compression zone so that the position of the neutral fiber is lowered because there is more material below it. The allowable stress in the traction zone can therefore be increased. The figure below shows a diagram of the proposed cross-section (Figure 1).

The torque, change of curvature, and material are considered to be known. The inertia value can be obtained using Equation (1). The inertia is used to calculate the distances from the neutral fiber to the skins with the most tensile and compression load so that both are working at $100 \%$ of their capacity.

$$
\begin{aligned}
& h_{T \max }=\frac{I_{Z} * \sigma_{a d m T}}{M} \\
& h_{C \max }=\frac{I_{Z} * \sigma_{a d m C}}{M}
\end{aligned}
$$

In addition to these, the equations that determine the position the cross-section's neutral fiber and calculate its inertia are proposed.

$$
\begin{gathered}
y_{G}=\frac{e_{T}+\left(\frac{e_{T}}{2}+e_{C}\right)+n\left(\frac{e_{C}^{2}}{2}\right)}{e_{T}+n * e_{c}} \\
I_{Z}=b *\left(\frac{1}{12} e_{T}^{3}+e_{T}\left(e_{c}+\frac{e_{T}}{2}-y_{G}\right)^{2}+\frac{n}{12} e_{C}^{3}+n * e_{C}\left(\frac{e_{C}}{2}-y_{G}\right)^{2}\right)
\end{gathered}
$$

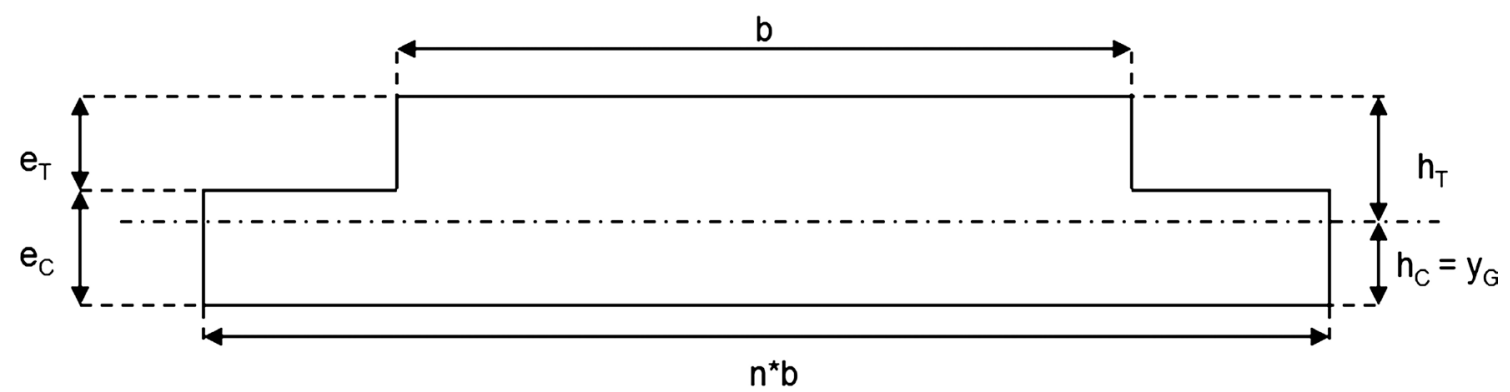

Figure 1. Base diagram of the proposed resistant cross-section. 
In general, in these materials, the maximum tensile stress is greater than the maximum compression stress. In order for the compression skin to work at $100 \%$, the following must be true:

$$
y_{G}=h_{\max C}
$$

If the traction skin is to work at its maximum capacity, the following must also be true:

$$
e_{T}=h_{\max C}+h_{T \max }-e_{C}
$$

There are therefore more equations (Equations (4)-(11)) than unknowns at this point in the design process. Using only the restriction that maximizes the admissible compression stress seems logical. Values are given to the thickness of the zone with width $b\left(e_{T}\right)$ and to the width factor $(n)$ (Figure 1 ). This generates the value of the thickness of the zone with width multiplied by a factor of $n\left(e_{C}\right)$ (Equations (8)-(10)):

$$
e_{C}=\frac{\left(h_{\max C} * n-e_{T}\right) \pm \sqrt{\left(e_{T}-h_{\max C} * n\right)^{2}-4\left(\frac{n}{2}\right)\left(\frac{e_{T}^{2}}{2}-h_{\max C} * e_{T}\right)}}{n}
$$

Of the two possible values generated by solving the quadratic equation, only those in which the square root is found by adding have a physical value, because negative thicknesses would be obtained if this was done by subtraction.

The width of the cross-section (b) can be obtained from Equation (9):

$$
b=\frac{I_{Z}}{\frac{e_{T}^{3}}{12}+e_{T}\left(e_{C}+\frac{e_{T}}{2}-y_{G}\right)^{2}+n \frac{e_{C}^{3}}{12}+n * e_{C}\left(\frac{e_{C}}{2}-y_{G}\right)^{2}}
$$

The final value of $h_{T}$ would be:

$$
h_{T}=e_{T}+e_{C}-h_{C \max }
$$

Giving values to the traction thickness and the width factor, it is possible to calculate the energy density per unit of weight (Equation $((4),(5))$ ), which in this particular case can be written

$$
\frac{U}{P}=\frac{\left(\frac{\sigma_{a d m T}}{h_{\max T}}\right)^{2}\left(\frac{h_{T}^{3}+n * h_{C}^{3}+(n-1)\left(e_{C}-h_{C}\right)^{3}}{6 E_{T}}\right)}{\rho\left(e_{T}+n * e_{C}\right)}
$$

\section{Example of Design and Analysis of the Parametrization $e_{T}-\boldsymbol{n}$}

Resin epoxy and S2 glass fiber will be used because of their excellent mechanical properties. The characteristics of both components are shown below. [Ashby, 2010]

- S2 glass fiber. Tensile strength $=4.89 \times 10^{9} \mathrm{~Pa}$ Young's Modulus $=8.69 \times 10^{10}$ Pa. Density $=2530 \mathrm{~kg} / \mathrm{m}^{3}$.

- Gairesa epoxy resin. Tensile strength $=6.50 \times 10^{7} \mathrm{~Pa}$ Young's Modulus $=1.30$ 
$\times 10^{9} \mathrm{~Pa}$. Density $=1200 \mathrm{~kg} / \mathrm{m}^{3}$.

The characteristics of the resulting composite of $60 \% \mathrm{~S} 2$ glass fiber by weight in an epoxy matrix are:

- Allowable tensile strength $=2.37 \times 10^{9} \mathrm{~Pa}$.

- Allowable compression strength $=1.18 \times 10^{9} \mathrm{~Pa}$.

- Young's Modulus = $5.27 \times 10^{10} \mathrm{~Pa}$.

- Allowable tensile elongation: $4.5 \%$.

- Density $=1998 \mathrm{~kg} / \mathrm{m}^{3}$.

A change of curvature of and a torque of $M=6667 \mathrm{~N} \cdot \mathrm{m}$ will be considered; for a width factor of $n=2$. Table 1 shows the results obtained for the thickness of the traction skin [20] and [21].

The position of the neutral fiber is such that the stress on the skin that is experiencing greater compression load always matches the admissible value; the difference between the different cases is the thickness of the zone of the section with the narrowest width. Although the position of the neutral fiber and the inertia of the cross-section coincide in all cases, the energy density varies. The row highlighted in green contains the dimensions and characteristics of the optimized monolithic cross-section. The maximum stress does not coincide with the maximum energy density, because it reaches a point at which even though the stress in the traction zone begins to decrease, the total thickness of the crosssection also decreases; the traction stress that is achieved is very close to the maximum. This decrease in thickness offsets the drop in stress and the energy density therefore increases until it reaches the optimum cross-section with respect

Table 1. Resistant cross-section design table for a fixed change of curvature, applied torque, and width factor).

\begin{tabular}{|c|c|c|c|c|c|c|c|c|c|}
\hline$e_{T}(\mathrm{~m})$ & $e_{C}(\mathrm{~m})$ & Fibra neutra $(\mathrm{m})$ & $h_{C}(\mathrm{~m})$ & $h_{T}(\mathrm{~m})$ & $b(\mathrm{~m})$ & $I_{Z}\left(\mathrm{~m}^{4}\right)$ & $\sigma_{\max T}(\mathrm{~Pa})$ & $\sigma_{\max C}(\mathrm{~Pa})$ & $U / P(\mathrm{Wh} / \mathrm{kg})$ \\
\hline $1.02 \times 10^{-02}$ & $1.02 \times 10^{-02}$ & $1.02 \times 10^{-02}$ & $1.02 \times 10^{-02}$ & $1.02 \times 10^{-02}$ & $8.09 \times 10^{-02}$ & $5.75 \times 10^{-08}$ & $1.18 \times 10^{09}$ & $1.18 \times 10^{09}$ & $6.17 \times 10^{-01}$ \\
\hline $7.00 \times 10^{-03}$ & $1.63 \times 10^{-02}$ & $1.02 \times 10^{-02}$ & $1.02 \times 10^{-02}$ & $1.31 \times 10^{-02}$ & $3.74 \times 10^{-02}$ & $5.75 \times 10^{-08}$ & $1.52 \times 10^{09}$ & $1.18 \times 10^{09}$ & $6.87 \times 10^{-01}$ \\
\hline $8.00 \times 10^{-03}$ & $1.56 \times 10^{-02}$ & $1.02 \times 10^{-02}$ & $1.02 \times 10^{-02}$ & $1.34 \times 10^{-02}$ & $3.67 \times 10^{-02}$ & $5.75 \times 10^{-08}$ & $1.55 \times 10^{09}$ & $1.18 \times 10^{09}$ & $7.07 \times 10^{-01}$ \\
\hline $9.00 \times 10^{-03}$ & $1.49 \times 10^{-02}$ & $1.02 \times 10^{-02}$ & $1.02 \times 10^{-02}$ & $1.37 \times 10^{-02}$ & $3.60 \times 10^{-02}$ & $5.75 \times 10^{-08}$ & $1.58 \times 10^{09}$ & $1.18 \times 10^{09}$ & $7.30 \times 10^{-01}$ \\
\hline $1.00 \times 10^{-02}$ & $1.41 \times 10^{-02}$ & $1.02 \times 10^{-02}$ & $1.02 \times 10^{-02}$ & $1.39 \times 10^{-02}$ & $3.53 \times 10^{-02}$ & $5.75 \times 10^{-08}$ & $1.61 \times 10^{09}$ & $1.18 \times 10^{09}$ & $7.54 \times 10^{-01}$ \\
\hline $1.10 \times 10^{-02}$ & $1.33 \times 10^{-02}$ & $1.02 \times 10^{-02}$ & $1.02 \times 10^{-02}$ & $1.41 \times 10^{-02}$ & $3.47 \times 10^{-02}$ & $5.75 \times 10^{-08}$ & $1.64 \times 10^{09}$ & $1.18 \times 10^{09}$ & $7.80 \times 10^{-01}$ \\
\hline $1.20 \times 10^{-02}$ & $1.25 \times 10^{-02}$ & $1.02 \times 10^{-02}$ & $1.02 \times 10^{-02}$ & $1.43 \times 10^{-02}$ & $3.42 \times 10^{-02}$ & $5.75 \times 10^{-08}$ & $1.65 \times 10^{09}$ & $1.18 \times 10^{09}$ & $8.07 \times 10^{-01}$ \\
\hline $1.30 \times 10^{-02}$ & $1.16 \times 10^{-02}$ & $1.02 \times 10^{-02}$ & $1.02 \times 10^{-02}$ & $1.44 \times 10^{-02}$ & $3.37 \times 10^{-02}$ & $5.75 \times 10^{-08}$ & $1.67 \times 10^{09}$ & $1.18 \times 10^{09}$ & $8.34 \times 10^{-01}$ \\
\hline $1.40 \times 10^{-02}$ & $1.07 \times 10^{-02}$ & $1.02 \times 10^{-02}$ & $1.02 \times 10^{-02}$ & $1.44 \times 10^{-02}$ & $3.35 \times 10^{-02}$ & $5.75 \times 10^{-08}$ & $1.67 \times 10^{09}$ & $1.18 \times 10^{09}$ & $8.61 \times 10^{-01}$ \\
\hline $1.50 \times 10^{-02}$ & $9.66 \times 10^{-03}$ & $1.02 \times 10^{-02}$ & $1.02 \times 10^{-02}$ & $1.44 \times 10^{-02}$ & $3.35 \times 10^{-02}$ & $5.75 \times 10^{-08}$ & $1.67 \times 10^{09}$ & $1.18 \times 10^{09}$ & $8.86 \times 10^{-01}$ \\
\hline $1.60 \times 10^{-02}$ & $8.58 \times 10^{-03}$ & $1.02 \times 10^{-02}$ & $1.02 \times 10^{-02}$ & $1.44 \times 10^{-02}$ & $3.39 \times 10^{-02}$ & $5.75 \times 10^{-08}$ & $1.66 \times 10^{09}$ & $1.18 \times 10^{09}$ & $9.07 \times 10^{-01}$ \\
\hline $1.70 \times 10^{-02}$ & $7.39 \times 10^{-03}$ & $1.02 \times 10^{-02}$ & $1.02 \times 10^{-02}$ & $1.42 \times 10^{-02}$ & $3.48 \times 10^{-02}$ & $5.75 \times 10^{-08}$ & $1.64 \times 10^{09}$ & $1.18 \times 10^{09}$ & $9.22 \times 10^{-01}$ \\
\hline $1.80 \times 10^{-02}$ & $6.06 \times 10^{-03}$ & $1.02 \times 10^{-02}$ & $1.02 \times 10^{-02}$ & $1.38 \times 10^{-02}$ & $3.66 \times 10^{-02}$ & $5.75 \times 10^{-08}$ & $1.60 \times 10^{09}$ & $1.18 \times 10^{09}$ & $9.24 \times 10^{-01}$ \\
\hline $1.90 \times 10^{-02}$ & $4.49 \times 10^{-03}$ & $1.02 \times 10^{-02}$ & $1.02 \times 10^{-02}$ & $1.33 \times 10^{-02}$ & $4.03 \times 10^{-02}$ & $5.75 \times 10^{-08}$ & $1.54 \times 10^{09}$ & $1.18 \times 10^{09}$ & $9.04 \times 10^{-01}$ \\
\hline $2.00 \times 10^{-02}$ & $2.33 \times 10^{-03}$ & $1.02 \times 10^{-02}$ & $1.02 \mathrm{E}-02$ & $1.21 \times 10^{-02}$ & $5.05 \times 10^{-02}$ & $5.75 \times 10^{-08}$ & $1.40 \times 10^{09}$ & $1.18 \times 10^{09}$ & $8.19 \times 10^{-01}$ \\
\hline
\end{tabular}


to energy storage (highlighted in yellow in the table above). Beyond that maximum value, the energy density value begins to decrease.

The energy density that could theoretically be reached with this cross-section is $0.924 \mathrm{Wh} / \mathrm{kg}$, resulting in an increase of approximately $50 \%$ with respect to the optimized rectangular cross-section [20] and [21].

Once this base design has been completed, it is important to note that although for larger widths in the lower zone of the cross-section, the increase in energy density that is generated does not compensate for the increased complexity of the cross-section.

\section{Optimization of the Base Design}

The design above could generate some manufacturing difficulties, such as the appearance of stress concentrators, despite the inclusion of fillet radii. To avoid all of these problems, the simplest solution consists of softening the transition between the two zones of the cross-section to avoid sudden changes in the lines of force. It is important to be careful because when this change is made, both the position of the neutral fiber and the value of the moment of geometric inertia that were calculated in the theoretical model will change. The changes that are made must be offset by adding or removing material in the corresponding zones. This can be done iteratively using existing CAD programs, because they quickly return the aforementioned two values.

In addition, near the neutral fiber, there is a region of material that is hardly working, and will therefore not store energy; its only contribution is to add weight to the unit, reducing the energy density. To attempt to prevent this, several holes can be drilled in this zone; with an adequate diameter, the impact that they will have on the position of the neutral fiber and the moment of inertia of the cross-section will be minimal. The design in Figure 2 is modified, Figure 3, with these two design criteria.

For this design, the following values are obtained for the position of the neutral fiber $y_{G}=10.45 \mathrm{~mm}$ (with respect to the furthest fiber in the traction zone) and for the moment of geometric inertia $I_{Z}=5.81 \times 10^{-8} \mathrm{~m}^{4}$. The variation in

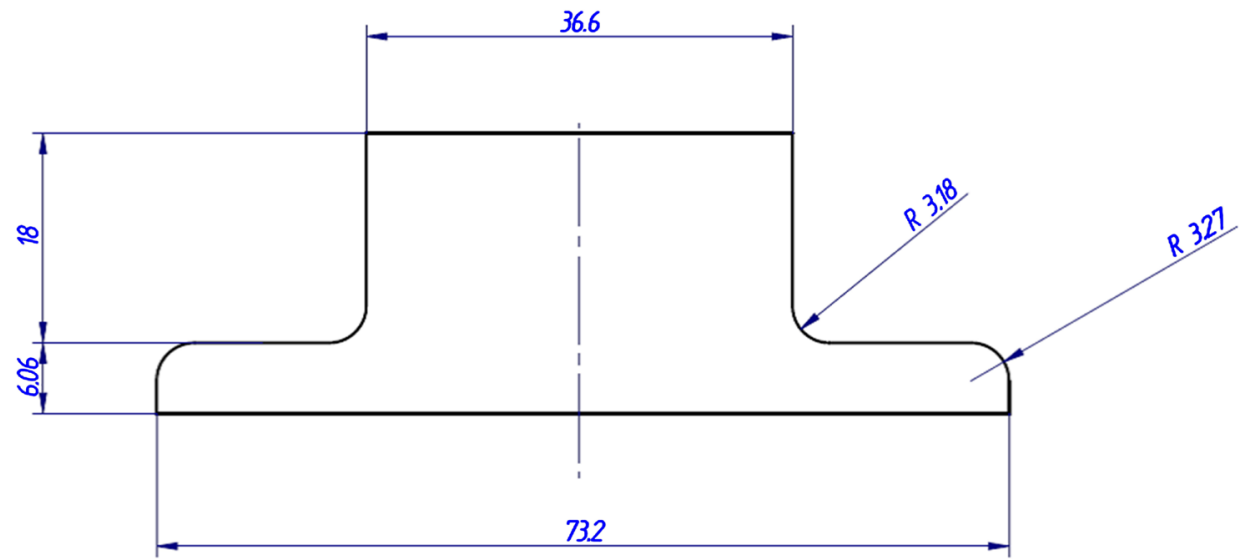

Figure 2. First optimization of the extruded resistant cross-section. 
these values is minimal with respect to the equivalents in the initial design $\left(y_{G}=\right.$ $\left.10.45 \mathrm{~mm} ; I_{Z}=5.75 \times 10^{-8} \mathrm{~m}^{4}\right)$. The other principal dimensions of the cross-section are shown in Figure 3.

With these dimensions, the process for calculating the energy density is the same as the one described in the previous section; however, due to the fact that extending the integral to the defined area is overly complicated, it will be divided into single areas so that the calculation is simpler and there is minimal error.

The energy density of each one of the areas into which the cross-section is divided is calculated. For any prism element (height $\mathrm{d} y$, width $\mathrm{d} x$ and length $\mathrm{d} z$ ), the integral of the energy density can be written as

$$
\begin{aligned}
U & =\iiint \frac{1}{2} \frac{\sigma^{2}}{E} \mathrm{~d} V=\iiint \frac{1}{2 E}\left(\frac{\sigma_{a d m T}}{h_{T \max }} y\right)^{2} \mathrm{~d} x \mathrm{~d} y \mathrm{~d} z \\
& =\left(\frac{\sigma_{a d m T}}{h_{T \max }}\right)^{2} \frac{Z * X}{2 E} \int_{a}^{b} y^{2} \mathrm{~d} y \\
& =\left(\frac{\sigma_{a d m T}}{h_{T \max }}\right)^{2} \frac{Z * X}{6 E}\left[y^{3}\right]_{a}^{b}
\end{aligned}
$$

This formula can be applied specifically to each one of the areas defined previously (Figure 4 ). Note that $X$ now refers to the specific width of each one, and $Z$ is any generic length.

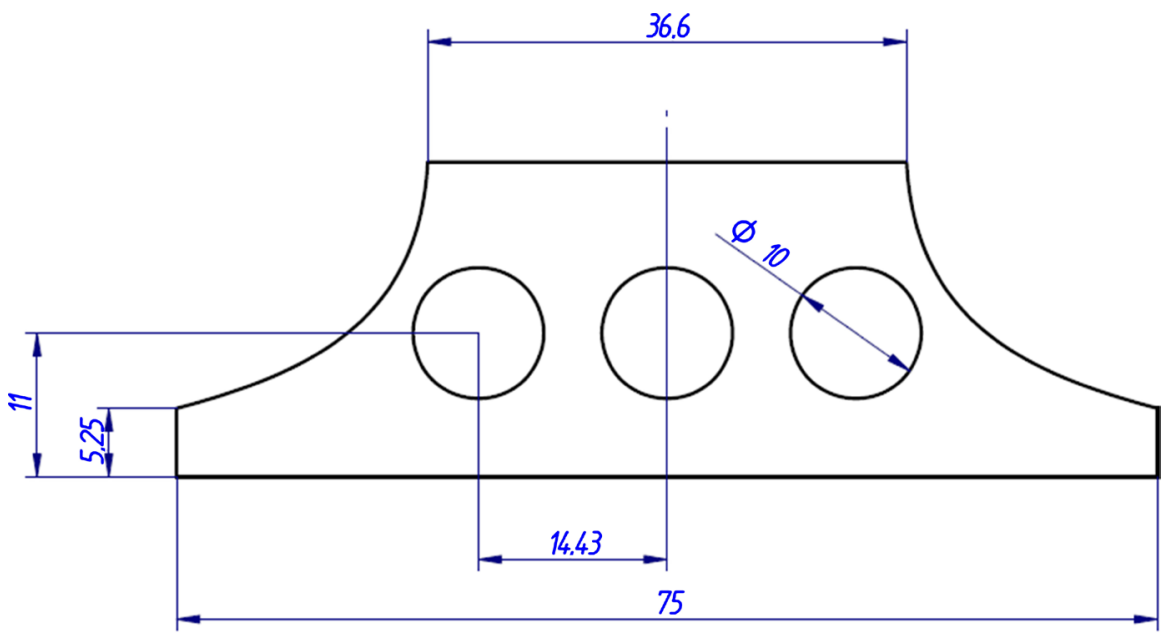

Figure 3. Second optimization of the extruded resistant cross-section.

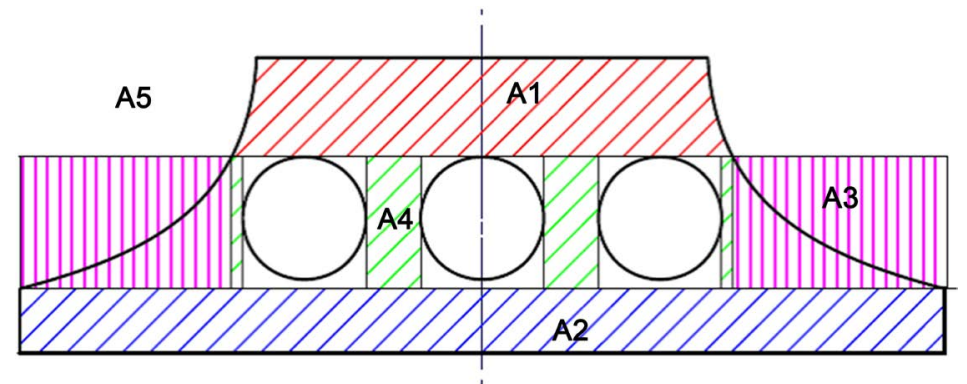

Figure 4. Zone division for the calculation of the second extruded resistant cross-section. 
Area 1: zone under traction with maximum energy storage.

$$
U_{1}=\left(\frac{\sigma_{a d m T}}{h_{T \max }}\right)^{2} \frac{Z * b_{1}}{6 E} *\left(\left(e_{T}-y_{G}\right)^{3}-\left(\frac{\phi}{2}+d_{1}-y_{G}\right)^{3}\right)
$$

Area 2: zone under compression.

$$
U_{2}=\left(\frac{\sigma_{a d m T}}{h_{T \max }}\right)^{2} \frac{Z * b_{2}}{6 E} *\left(y_{G}^{3}-\left(y_{G}-e_{C}\right)^{3}\right)
$$

Areas 4 and 5: zone under traction and compression.

$$
\begin{gathered}
U_{4}=\left(\frac{\sigma_{a d m T}}{h_{T \max }}\right)^{2} \frac{Z *\left(d_{2}-\phi\right)}{6 E} *\left(\left(\frac{\phi}{2}+d_{1}-y_{G}\right)^{3}+\left(y_{G}-e_{C}\right)^{3}\right) \\
U_{5}=\left(\frac{\sigma_{a d m T}}{h_{T \max }}\right)^{2} \frac{Z * b_{3}}{6 E} *\left(\left(\frac{\phi}{2}+d_{1}-y_{G}\right)^{3}+\left(y_{G}-e_{C}\right)^{3}\right)
\end{gathered}
$$

Area 3:

This area does not correspond to any area in the cross-section; however, the rectangle that defines its diagonal is divided, resulting in two right triangles. Area 3 can be approximated by the area of a triangle.

With the neutral fiber positioned practically in the center of the rectangle, the stress distribution is virtually identical in both triangles. The energy accumulated by the cross-section is considered to correspond to half of the energy that the rectangle would store.

$$
\begin{aligned}
U_{3}= & \left(\frac{\sigma_{a d m T}}{h_{T \max }}\right)^{2} \frac{Z *\left(b_{2}-2 * b_{3}-3 * \phi-2 *\left(d_{2}-\phi\right)\right)}{12 E} \\
& *\left(\left(\frac{\phi}{2}+d_{1}-y_{G}\right)^{3}+\left(y_{G}-e_{C}\right)^{3}\right)
\end{aligned}
$$

The total energy density by volume units will be:

$$
\frac{U}{P}=\frac{U_{1}+U_{2}+2\left(U_{3}+U_{4}+U_{5}\right)}{A * Z * \rho}
$$

For the specific case of Figure 3, Figure 4 and Figure 5, and the materials described above, there is a measured area with the CAD program of $A=1027.64 \mathrm{~mm}^{2}$. And adjusting the rest of the variables, the following energy density is obtained:

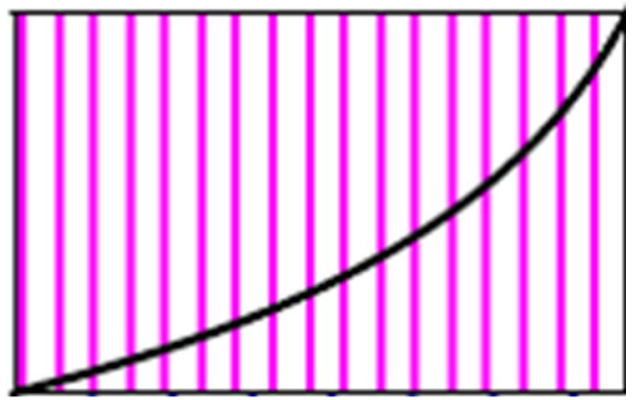

Figure 5. Details of the linearized calculation and error made. 


$$
\frac{U}{P}=0.977 \mathrm{Wh} / \mathrm{kg}
$$

\section{Design Optimized for Life under Fatigue}

The previous design was prepared taking the admissible stresses of the girder material into account. This made it possible to take maximum advantage of the material's capacity for energy storage. However, the girder fatigue was not analyzed.

For the S2 glass fiber used in the design, maximum tensile stresses of $965 \mathrm{MPa}$ could be reached, so the life span of the material is 10,000 cycles (data specified by the manufacturer). While the life span may be reduced by up to 200 cycles if working at the admissible stress. The operating tensile stress used was $965 \mathrm{MPa}$ and under compression, approximately half, $537 \mathrm{MPa}$. The reduction of the operating stress causes an increase in the height of the cross-section and a decrease in energy density.

The data in Table 2 was generated under these considerations and with the previous design, with the first row of the table corresponding to the case of a rectangular monolithic cross-section.

Using the original design data, the energy density drops drastically and the height of the cross-section also increases. If the change of curvature is increased, the height the curvature increases, which means that this volume must be reduced. However, this would in turn cause an increase in the thickness.

A parametric analysis is therefore required to see the influence of the different design parameters on the dimensions and the energy stored in the girder. In regard to the materials, the use of a fiber with better fatigue properties is also studied, as is the case of the HST carbon fiber, which reaches a maximum tensile strength of $1.25 \mathrm{GPa}$ and compression strength of $1 \mathrm{GPa}$, for a life span of 10,000 cycles.

Figures 6-8 show that the best option would be to select a cross-section with the smallest change of curvature possible because this is the one that will occupy the least space. They also show that the use of carbon fiber generates energy densities that are slightly higher than with glass fiber.

The drawback of using narrower cross-sections is that their thickness will be greater and energy density will increase, due to the fact that the outer fibers are further from the neutral fiber.

The energy density increases as the thickness of the traction skin increases

Table 2. Design alternatives for the resistant cross-section based on fatigue and life cycle criteria.

\begin{tabular}{cccccccccc}
\hline$e_{T}(\mathrm{~m})$ & $e_{C}(\mathrm{~m})$ & $h_{C}(\mathrm{~m})$ & $h_{T}(\mathrm{~m})$ & $b(\mathrm{~m})$ & I check & $\sigma_{\max T}(\mathrm{~Pa})$ & $\sigma_{\max C}(\mathrm{~Pa})$ & $U / P(\mathrm{Wh} / \mathrm{kg})$ & $e_{T}(\mathrm{~m})$ \\
\hline $4.63 \times 10^{-03}$ & $4.63 \times 10^{-03}$ & $4.63 \times 10^{-03}$ & $4.63 \times 10^{-03}$ & 2.17 & $1.44 \times 10^{-07}$ & $5.37 \times 10^{08}$ & $5.37 \times 10^{08}$ & $1.27 \times 10^{-01}$ & $4.63 \times 10^{-03}$ \\
$3.00 \times 10^{-03}$ & $7.52 \times 10^{-03}$ & $4.63 \times 10^{-03}$ & $5.88 \times 10^{-03}$ & 1.01 & $1.44 \times 10^{-07}$ & $6.82 \times 10^{08}$ & $5.37 \times 10^{08}$ & $1.40 \times 10^{-01}$ & $3.00 \times 10^{-03}$ \\
$4.00 \times 10^{-03}$ & $6.81 \times 10^{-03}$ & $4.63 \times 10^{-03}$ & $6.18 \times 10^{-03}$ & $9.69 \times 10^{-01}$ & $1.44 \times 10^{-07}$ & $7.16 \times 10^{08}$ & $5.37 \times 10^{08}$ & $1.49 \times 10^{-01}$ & $4.00 \times 10^{-03}$ \\
$9.00 \times 10^{-03}$ & $1.24 \times 10^{-03}$ & $4.63 \times 10^{-03}$ & $5.61 \times 10^{-03}$ & 1.28 & $1.44 \times 10^{-07}$ & $6.50 \times 10^{08}$ & $5.37 \times 10^{08}$ & $1.73 \times 10^{-01}$ & $9.00 \times 10^{-03}$ \\
\hline
\end{tabular}




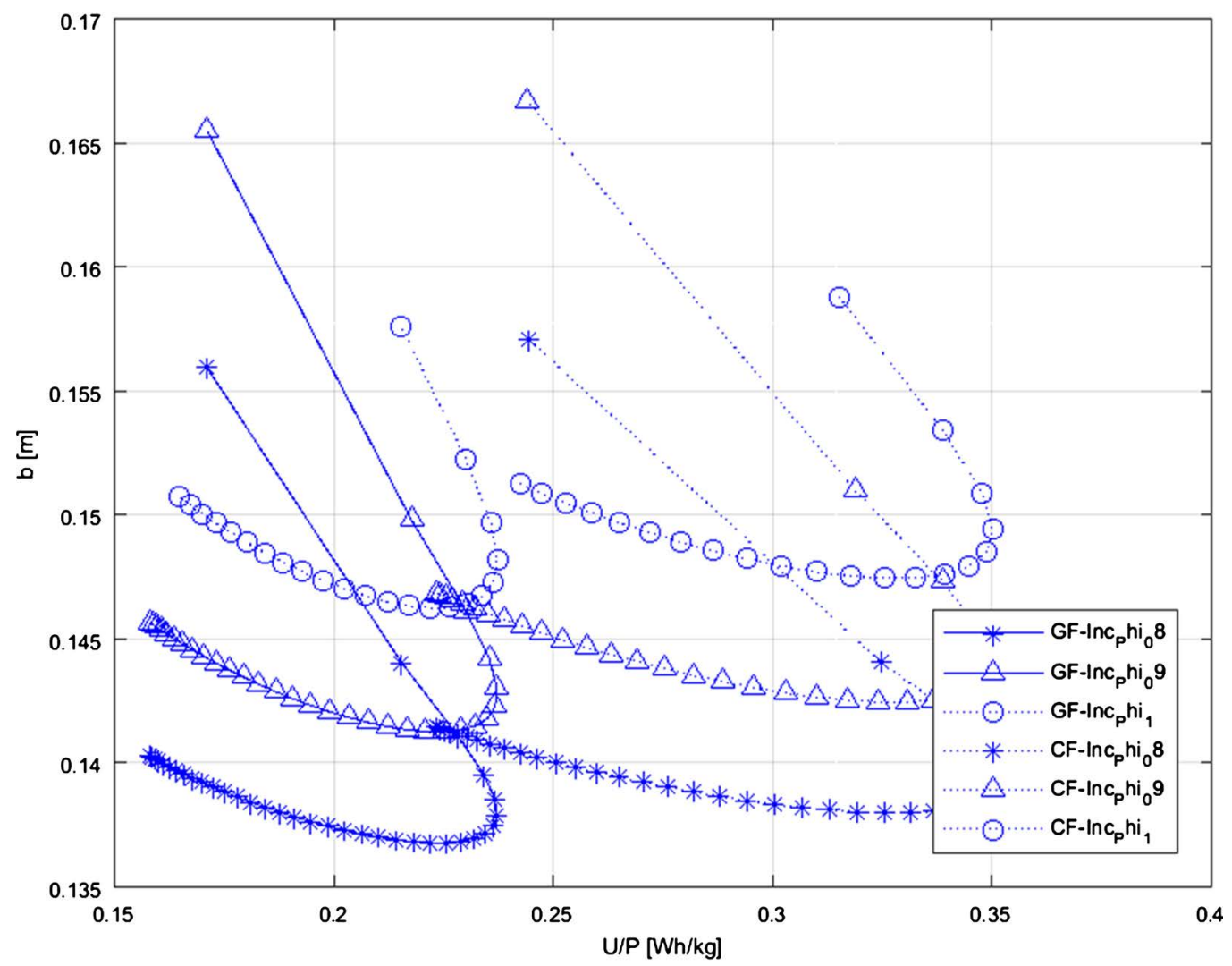

Figure 6. Evolution of energy per unit of volume with the change of curvature and width.

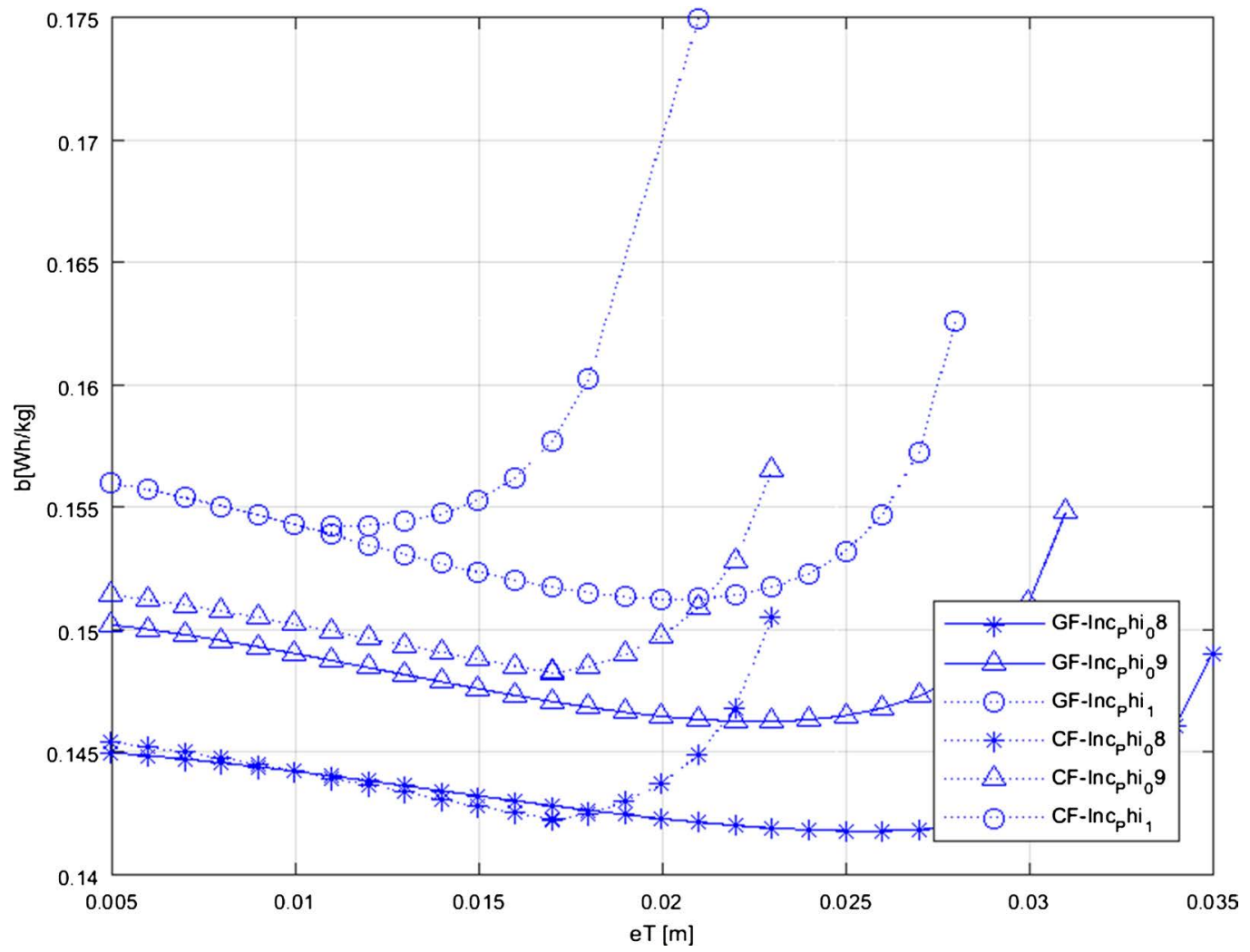

Figure 7. Evolution of the thickness of the traction zone with the change in curvature and width. 


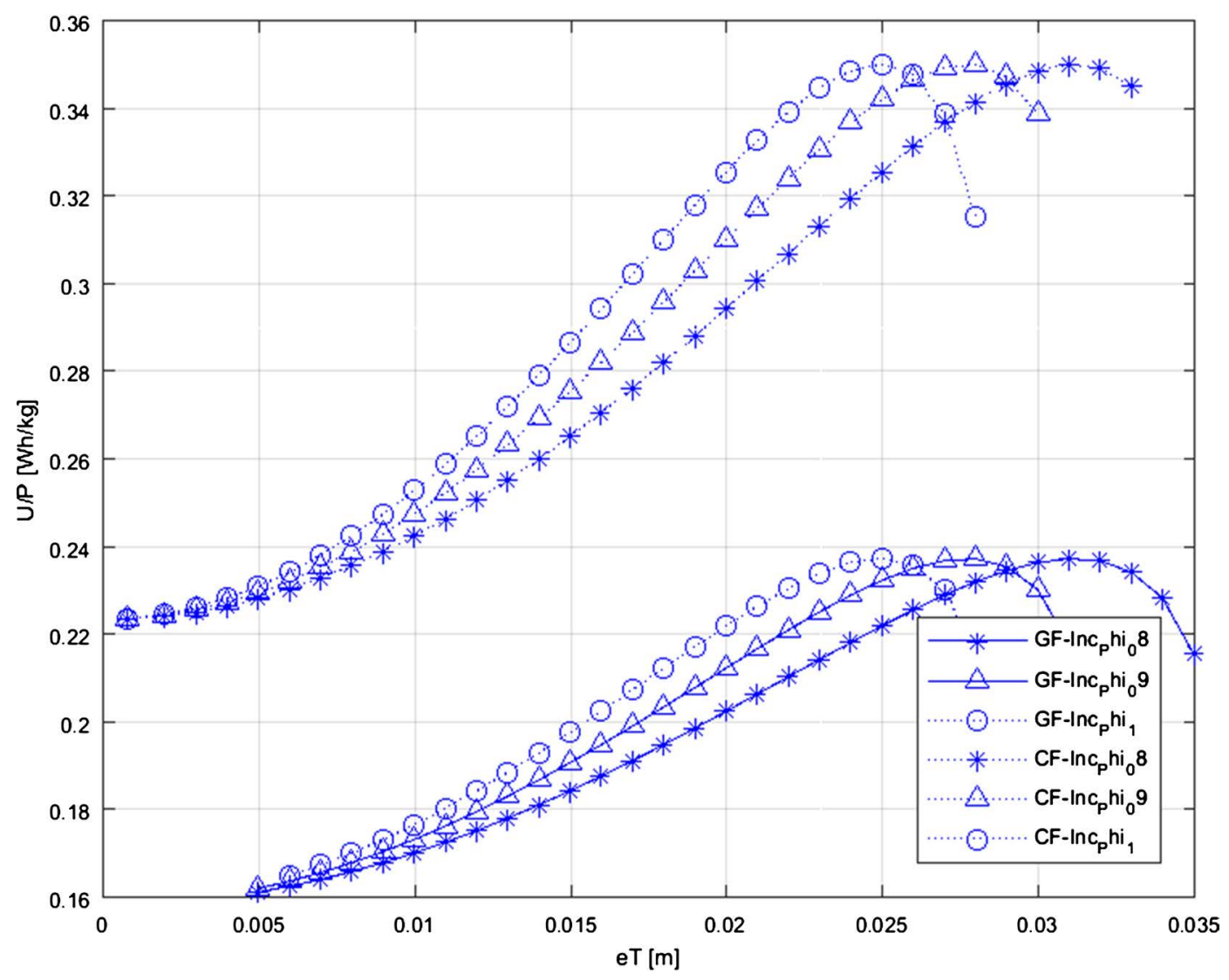

Figure 8. Evolution of energy per unit of volume with the change of curvature and width of the traction zone.

(and similarly, the thickness of the compression skin), until it reaches point at which the weight contributed by the material has a greater impact than the increase in admissible stress, which means that a point of inflection is reached, after which energy density decreases.

\section{Validation of the Designs Using FEM Simulations}

The decision was made to carry out finite element simulations [22] under pure bending to verify that the stresses achieved on the most heavily loaded skins of the cross-section coincide with those in the theoretical model.

The maximum tensile stresses on the upper skin of the girder are around 1.61 $\mathrm{GPa}$; versus the theoretical value of $1.60 \mathrm{GPa}$, which indicates minimal error (Figure 9(a)). In regard to the stresses on the compression skin furthest from the neutral fiber; these values reach values of around $-1.14 \mathrm{GPa}$, when the design stress is $-1.18 \mathrm{GPa}$ (Figure 9 (b)). The stresses predicted during the design process are therefore achieved, and consequently, practically all of the expected energy is stored.

\section{Conclusions}

A cross-section has been developed as an alternative to sandwich panels, to be manufactured using pultrusion techniques, thus avoiding the problems caused 


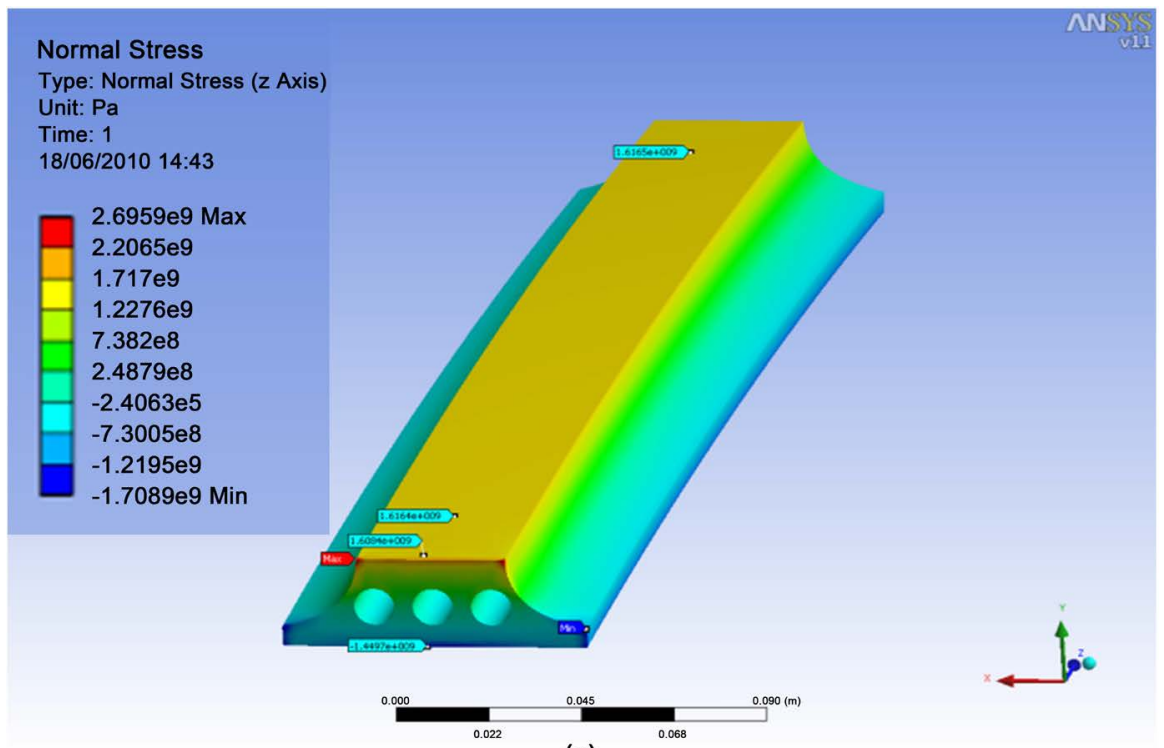

(a)

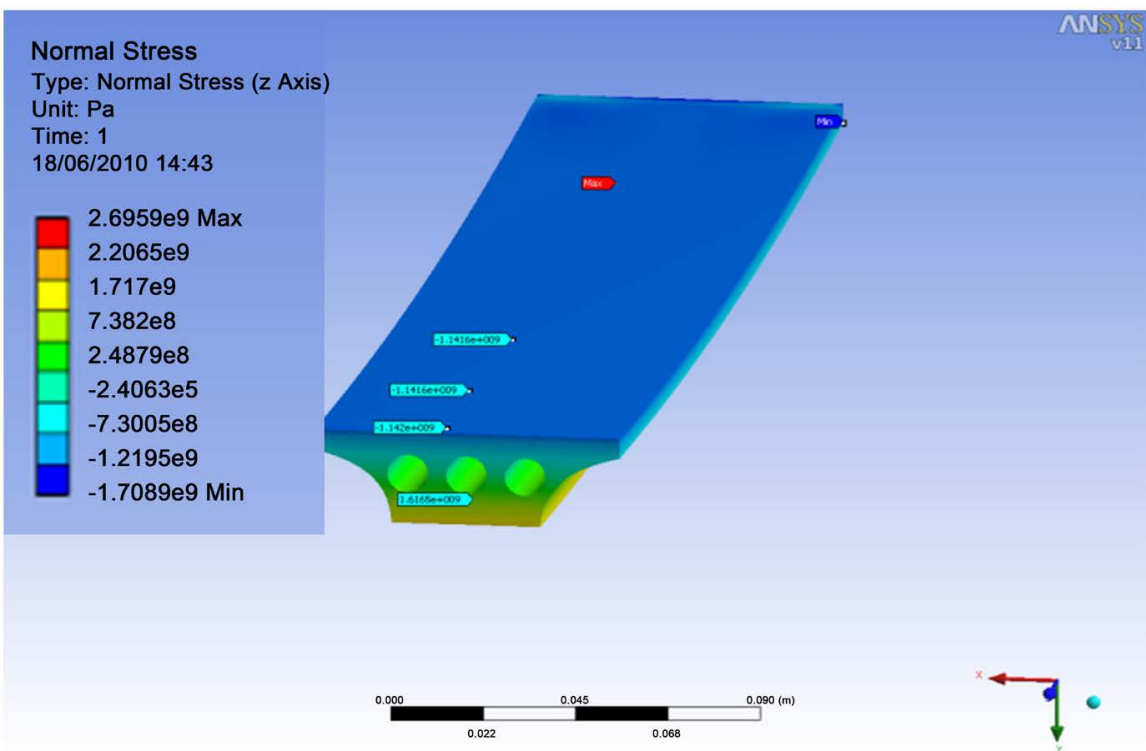

(b)

Figure 9. Stress state of under pure bending on the traction skin.

by the use of foam. The energy density of the new cross-section, working close to the allowable stress is approximately $1 \mathrm{Wh} / \mathrm{kg}$, which does not represent a significant loss with respect to the value generated by the equivalent sandwich board $(1.40 \mathrm{Wh} / \mathrm{kg})$ in comparison with the advantages generated by the new design.

However, the life span of a girder with this cross-section under fatigue may be short. To guarantee a life span of 10,000 cycles, the energy density of the crosssection is reduced to $0.226 \mathrm{Wh} / \mathrm{kg}$, which means that while it is an alternative to sandwich panels for the reasons mentioned above, it will not be an alternative in terms of energy storage, because it can reach a value of approximately $0.636 \mathrm{Wh} / \mathrm{kg}$.

A compromise can be reached between fatigue life span and quantity of stored energy, adjusting the stress to which the girder is subjected, and therefore the 
dimensions of the girder.

\section{Acknowledgements}

We would like to express my very great appreciation to Dr Muñoz Guijosa for his valuable and constructive suggestions during the planning and development of this research work. His willingness to give his time so generously has been very much appreciated.

\section{Conflicts of Interest}

The authors declare no conflicts of interest regarding the publication of this paper.

\section{References}

[1] Timoshenko, S. (1956) Strength of Materials, Part II, Advanced Theory and Problems. 3rd Edition, D. Vand Nostrand Company, New York.

[2] Timoshenko, S.P. and Goodier, J.N. (1970) Theory of Elasticity. McGraw-Hill, New York.

[3] Ortíz-Berrocal, L. (2007) Resistencia de Materiales. McGraw-Hill, Madrid.

[4] Ashby, M.F. (2010) Materials Selection in Mechanical Design. Butterworth Heinemann, Oxford.

[5] Miravete, A. (2000) Materiales Compuestos. Vol. I Editado por Antonio Miravete. Zaragoza.

[6] Andjelić, N. and Milosević-Mitić, V. (2012) Optimum Design of Thin-Wallet I-Beam Subjected to Stress Constraint. Journal of Theoretical and Applied Mechanics, 50, 987-999.

[7] Andjelić, N., Milosevic-Mitic, V. and Maneski, T. (2009) An Approach to the Optimization of Thin-Walled Z-Beam. Journal of Mechanical Engineering, 55, 742-748.

[8] Andjelić, N. (2003) Thin Walled I-Beam under Complex Loads-Optimization According to Stress Constraint. FME Transactions, 31, 55-60.

[9] Burgess, S.C. (1998) Shape Factors and Material Indices for Dimensionally Constrained Structures. Part 1: Beams. Journal of Mechanical Engineering Science, 212, 129-140. https://doi.org/10.1243/0954406981521097

[10] Galkiewicz, T., Krolak, M. and Kubiak, T. (2007) Optimization of Thin-Walled Beams Subjected to Bending in Respect of Local Stability and Strength. Mechanics and Mechanical Engineering, 11, 37-48.

[11] Hämäläinen, O.P. and Björk, T. (2013) Optimization of the Cross-Section of a Beam Subjected to Bending Load. In: Jármai, K. and Farkas, J., Eds., Design, Fabrication and Economy of Metal Structures, Springer, Berlin, Heidelberg.

[12] Pasini, D., Smith, D.J. and Burgess, S.C. (2003) Selection of Arbitrarily Scaled Cross-Sections in Bending Stiffness Design. Journal of Materials. Design and Applications, 217, 113-125.

[13] Pasini, D., Smith, D.J. and Burgess, S.C. (2003) Structural Efficiency Maps for Beams Subjected to Bending. Proceedings of the Institution of Mechanical Engineers, Part L: Journal of Materials Design and Applications, 217, 207-220. https://doi.org/10.1177/146442070321700303

[14] Ivelin, V. and Ivanov, I.I. (2006) Analysis, Modelling, and Optimization of Lami- 
nated Glasses as Plane Beam. International Journal of Solids and Structures, 43, 6887-6907. https://doi.org/10.1016/j.ijsolstr.2006.02.014

[15] Mehmet Zülfü, A. and Tezcan, S. (2005) A Mathematical Model for the Behavior of Laminated Glass Beams. Computers and Structures, 83, 1742-1753.

https://doi.org/10.1016/j.compstruc.2005.02.020

[16] Zolfaghari, A., Behravesh, A.H. and Adli, A. (2013) Continuous Glass Fiber Reinforced Wood Plastic Composite in Extrusion Process: Mechanical Properties. Materials and Design, 51, 701-708. https://doi.org/10.1016/j.matdes.2013.04.082

[17] Dahnke, C., Pietzka, D., Haase, M. and Tekkaya, A.E. (2014) Extending the Flexibility in the Composite Extrusion Process. Procedia CIRP, 18, 33-38. https://doi.org/10.1016/j.procir.2014.06.103

[18] Gardner, D.J. (2010) Extrusion of Wood Plastic Composites. University of Maine, Advanced Engineered Wood Composites Center, Orono, Maine 0446.

[19] Muñoz-Guijosa, J.M., Rodríguez de la Cruz, V., Fernández Caballero, D., et al. (2012) Simple Testing System for Pure Bending Tests with Large Deflections. Experimental Mechanics, 52, 679-692. https://doi.org/10.1007/s11340-011-9535-7

[20] Muñoz-Guijosa, J.M., Rodríguez de la Cruz, V., Fernández Caballero, D., et al. (2013) On the Use of Variable Bending Stiffness Clothoidal Strips for the Analysis and Synthesis of Low Variability Torque-Angle Turned Curves in Spiral Torsion Springs. Mechanism and Machine Theory, 67, 32-46.

https://doi.org/10.1016/j.mechmachtheory.2013.04.004

[21] Muñoz-Guijosa, J.M., Rodríguez de la Cruz, V., Fernández Caballero, D., et al. (2011) Generalized Spiral Torsion Spring Model. Mechanism and Machine Theory, 51, 110-130. https://doi.org/10.1016/j.mechmachtheory.2011.12.007

[22] (2013) ANSYS 15.0. ANSYS Inc., Canonsburg. 